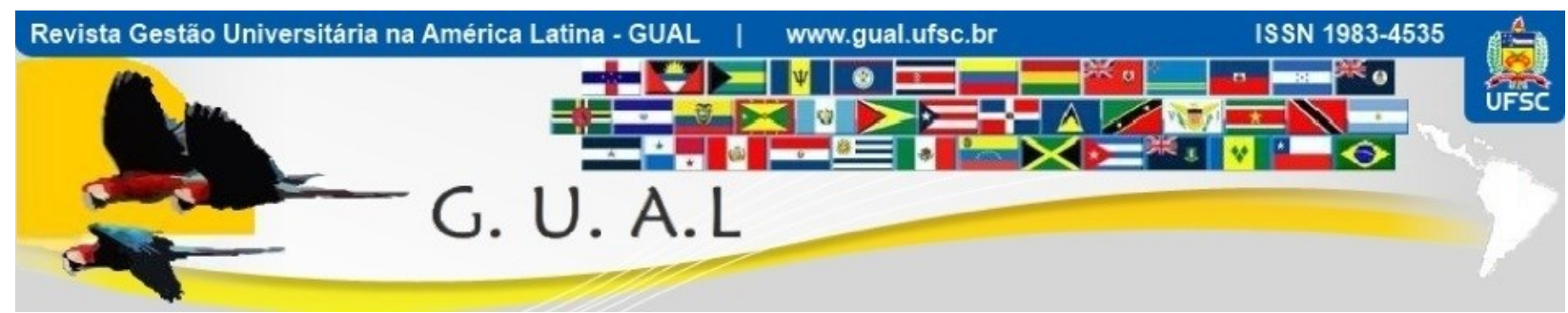

DOI: http://dx.doi.org/10.5007/1983-4535.2017v10n1p213

\title{
PERFIL PROFISSIONAL DOS DOCENTES DO CURSO DE ADMINISTRAÇÃO DA UNESPAR/FAFIPAR
}

\section{PROFESSIONAL PROFILE OF TEACHERS OF MANAGEMENT COURSE UNESPAR/FAFIPAR}

Paulo Roberto Wilkom, Especialista

Faculdade Estadual de Filosofia, Ciências e Letras de Paranaguá - FAFIPAR/UNESPAR paulo.wilkom@pr.senai.br

Accácio Mariano Fernandes, Graduado Faculdade Estadual de Filosofia, Ciências e Letras de Paranaguá - FAFIPAR/UNESPAR accaciofernandes@msn.com

Suelen Ramos Chagas, Especialista Faculdade Estadual de Filosofia, Ciências e Letras de Paranaguá - FAFIPAR/UNESPAR suelenrchagas@gmail.com

Recebido em 23/janeiro/2015

Aprovado em 14/novembro/2016

Sistema de Avaliação: Double Blind Review

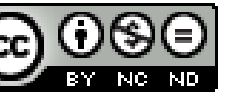

Esta obra está sob uma Licença Creative Commons Atribuição-Uso. 


\title{
RESUMO
}

O presente estudo pretende oferecer ao leitor uma visão sistêmica sobre o processo de ensinoaprendizagem oferecido pelo curso de Administração da UNESPAR/FAFIPAR. É ambição deste trabalho servir como ferramenta de análise tanto pelos professores da instituição, quanto para a própria academia em estudo e toda a faceta da sociedade ou cidadão que busque novos horizontes para compreender o processo de ensino-aprendizagem. Não se busca aqui, também, distinção entre professores ou disciplinas, haja vista que o construto social ao qual o ensino de administração está sujeito é dinâmico, prático e almeja sempre a melhoria, pois em última análise, poderá disponibilizar para a sociedade e mercado de trabalho egressos com competências superiores e conscientes de si e do ambiente em que vivem. Há um capítulo destinado à fundamentação teórica, pois busca situar o leitor em qual estágio o ensino de administração se encontra, um capítulo específico para a pesquisa propriamente dita, onde foram demonstrados graficamente os dados coletados, incorrendo também em uma análise com embasamento teórico e, posteriormente, sugestões que podem ser acrescidas ou levadas em consideração. Há muito foi introduzido o ensino superior no Brasil, porém, quando se fala do curso de Administração, esse veio com o advento da necessidade de profissionais com conhecimentos específicos para atuarem na máquina do Estado.

Palavras-chave: Administração. Pesquisa. Ensino Superior.

\begin{abstract}
This study aims to give the reader a systemic view of the process of teaching and learning offered by the course of Directors of UNESPAR / FAFIPAR. It ambition of this work serve as an analysis tool by both the teachers of the institution, and for the own academy in study and any facet of society or citizen who seeks new horizons to understand the process of teaching and learning. No search is here, too, the distinction between teachers and disciplines, given the fact that the social construct to which the board of education is subject is dynamic, practical and always strives for improvement, because in the final analysis, can provide for the society and market work graduates with higher skills and aware of themselves and the environment they live in. There is a chapter for the theoretical foundation, as to situate the reader in what stage management education is a specific chapter for the research itself, which was graphically demonstrated the collected data, also engaging in an analysis with theoretical and, later suggestions that can be added or taken into account. It has long been entered higher education in Brazil, however, when speaking of course of service, that came with the advent of the need for professionals with specific knowledge to work in the state machine.
\end{abstract}

Keywords: Administration. Research. Higher Education. 


\section{INTRODUÇÃO}

O presente estudo pretende oferecer ao leitor uma visão sistêmica sobre o processo de ensino aprendizagem oferecido pelo curso de Administração da UNESPAR/FAFIPAR. É ambição deste trabalho servir como ferramenta de análise tanto pelos professores da instituição, quanto para a própria academia em estudo e toda e faceta da sociedade ou cidadão que busque novos horizontes para compreender o processo de ensino aprendizagem. Não se busca aqui, também, distinção entre professores ou disciplinas, haja vista que o construto social ao qual o ensino de administração está sujeito é dinâmico, prático e almeja sempre a melhoria, pois em ultima analise, poderá disponibilizar para a sociedade e mercado de trabalho egressos com competências superiores e conscientes de si e do ambiente em que vivem. Para boa compreensão, este estudo dividiu-se em descriminação dos objetivos geral e específicos, bem como a metodologia que foi utilizada. Há um capítulo destinado à fundamentação teórica, pois busca situar o leitor em qual estágio o ensino de administração se encontra, um capítulo especifico para a pesquisa propriamente dita, onde foi demonstrado graficamente os dados coletados, incorrendo também em uma análise com embasamento teórico e, posteriormente, sugestões que podem ser acrescidas ou levadas em consideração. Por fim, apresenta-se a bibliográfica utilizada, onde se tem como intenção demonstrar a fidelidade dos dados apresentados.

O estudo objetiva desenvolver um levantamento sobre o perfil profissional dos docentes do curso de Administração da UNESPAR/FAFIPAR, com base nas perspectivas clássica, humanista e moderna. Para tanto, alguns objetivos específicos são necessários para orientar o desenvolvimento da pesquisa. Estes objetivos são: Estudar as práticas desenvolvidas em sala de aula pelos docentes do curso de Administração da UNESPAR/FAFIPAR; Delinear um perfil do curso com base nas práticas desenvolvidas em sala de aula; Traçar um paralelo entre a teoria pesquisada e a pesquisa prática, objetivando sugerir possíveis mudanças no escopo de curso de administração da UNESPAR/FAFIPAR.

Para o desenvolvimento do estudo a metodologia do trabalho consistiu em fontes primárias e secundárias, onde se realizou uma pesquisa bibliográfica de publicações já existentes pertinentes ao tema. Esta pesquisa é de natureza quantitativa e utilizou-se do método indutivo. A tipologia é classificada como descritiva, pois procura expor o comportamento de uma determinada população referente a um assunto específico. Ora, para argumentar sobre a metodologia e o método escolhido, os autores se utilizam das ideias de 
Lakatos e Marconi (2010), quando afirmam que a característica da pesquisa quantitativa é o seu positivismo. As autoras vão ainda mais longe ao discorrer que o processo indutivo, assim como o dedutivo, levam a algumas premissas. A diferença inequívoca é que na concepção dedutiva essas premissas são corroboradas com conclusões verdadeiras, nas premissas que são derivadas de observações isso não ocorre, o que se identifica são apenas as possibilidades.

Para a obtenção dos dados primários foi realizado a aplicação de um questionário, com perguntas abertas e fechadas, por amostragem, para 09 professores do curso de Administração da FAFIPAR, com o intuito de identificar as metodologias de ensino superior trabalhadas em aula com os alunos. Para esta coleta de dados foi utilizado a ferramenta do Google Docs, para tentar abranger uma maior parte da população.

\section{REFERENCIAL TEÓRICO}

\subsection{BREVE HISTÓRICO DO ENSINO DE ADMINISTRAÇÃO NO BRASIL}

Há muito foi introduzido o ensino superior no Brasil, porém, quando se fala do curso de Administração, esse veio com o advento da necessidade de profissionais com conhecimentos específicos para atuarem na máquina do Estado. O crescimento econômico e o crescimento das empresas privadas também ajudaram a alavancar o ensino superior em Administração. De acordo com Pinto e Motter (2012, p. 02) foi criada em 1944 a Fundação Getúlio Vargas (FGV), “com o objetivo de desenvolver pesquisa e ensino na área da Administração".

Segundo os autores, a FGV em 1952 criou a Escola Brasileira de Administração Pública (EBAP), no Rio de Janeiro, sendo esta a primeira escola de administração pública da américa latina. Já em 1954 surge a Escola de Administração de Empresas de São Paulo (EAESP), sendo hoje a referencia na área de Administração.

Porém, foi em 1965 que foi regulamentada a profissão do Administrador, trazendo com isso mudanças nos currículos dos cursos, e estes tinham que adequar-se às exigências do mercado e às novas tecnologias que estavam sendo inseridas no ambiente de trabalho.

No site do CFA (Conselho Federal de Administração) (2014), pode-se encontrar um texto afirmando que durante a história, o ensino de administração de Administração no Brasil passou por dois momentos marcados por currículos mínimos aprovados em 1966 e 1993 . O texto afirma ainda que essas propostas culminaram na elaboração de diretrizes curriculares para os cursos de graduação em Administração. 
Com a crescente demanda do século XX pela busca de um diploma, o ensino superior passou a ofertar muito mais vagas, principalmente nas instituições privadas, que, segundo o CRA (2014), eram responsáveis na década de 80 por $79 \%$ dos alunos. A tabela abaixo mostra a o crescimento dos cursos de Administração no Brasil:

Tabela 1 Número de cursos segundo as décadas de 60, 70, 80, 90 e 2000.

\begin{tabular}{cc} 
DÉCADAS & NÚMERO DE CURSOS \\
\hline Antes de 1960 & 2 \\
1960 & 31 \\
1970 & 247 \\
1980 & 305 \\
1990 & 823 \\
2000 & 1.462 \\
2010 & 1.805 \\
\hline
\end{tabular}

Fonte: Site CRA (MEC - Dados compilados pelo Conselho Federal de Administração).

Se comparar os dados, observa-se um nítido crescimento dos cursos de administração. O CRA (2014) discorre que a abertura de cursos era vantajosa, ao menos aparentava ser, já que não existia um grande dispêndio financeiro para sua estruturação. Os cursos eram, na verdade, investimentos a curto prazo, procurando adaptar suas praticas acadêmicas aos grandes centros que possuíam maior legitimidade.

Independente da instituição escolhida ser privada ou pública, o fato é que ano a ano cresce o número de matriculados em cursos de administração, conforme mostra a tabela abaixo:

Tabela 2 Resumo da evolução dos cursos de Administração no Brasil.

\begin{tabular}{|c|c|c|c|}
\hline Ano & IES & Matrículas & Concluintes \\
\hline 1960 & 31 & N/I & N/I \\
\hline 1970 & 164 & 66.829 & 5.276 \\
\hline 1980 & 247 & 134.742 & 21.746 \\
\hline 1990 & 320 & 174.330 & 22.394 \\
\hline 2000 & 821 & 338.789 & 35.658 \\
\hline 2002 & 1.158 & 493.104 & 54.656 \\
\hline 2003 & 1.710 & 576.305 & 64.792 \\
\hline 2004 & 2.048 & 641.455 & 88.466 \\
\hline
\end{tabular}

Fonte: Pinto e Motter, 2012.

\subsection{METODOLOGIAS DE ENSINO}

Cada vez mais as Instituições de Ensino Superior vêm se aperfeiçoando nas relações entre alunos e professores no campo do ensino e aprendizagem. Comenta Lima (1997, p. 44), 
que durante muito tempo acreditava-se que para um professor ser bom, bastava-lhe o domínio em um determinado campo de saber o qual ele lecionava e das pesquisas que desenvolvia. Quanto melhor pesquisador e maior a experiência, melhor era o professor. A autora salienta que, apesar desta visão equivocada, "tem sido crescente a preocupação com a formação de uma Didática do ensino Superior".

A reforma educacional de 1968, que reformula a estrutura e funcionamento do ensino superior, também traz consigo a "necessidade de buscar métodos mais adequados à formação de recursos humanos para o desenvolvimento do país" (LIMA, 1997, p. 45). Assim, começouse uma preocupação não somente com o conteúdo, mas como o modo que esse era passado, a fim de que os alunos absorvessem o máximo de informações para a prática da atividade.

O Curso Superior de Administração da FAFIPAR e os cursos de Administração em geral, trazem em seu currículo, uma diversidade de disciplinas de campos diferenciados das ciências, como Contabilidade, Direito, Economia, Sociologia, Matemática Financeira, Psicologia, etc. Enquanto uma disciplina envolve conteúdo quase que totalmente teórico, outra envolve cálculos, outra ainda, a prática, como os Jogos de Empresa. Difícil seria aplicar a mesma didática a todas as disciplinas, haja vista a distância de seus campos do saber.

Filho e Ribeiro (2008) atentam para o fato da constante mudança e consequente busca pelo novo para atender às demandas emergentes do mercado. Cada vez mais o aluno tem uma carga maior de conhecimentos que deve conceber durante sua formação, e também uma rápida obsolescência dessas informações. Os autores sugerem que devem ser inseridas na prática do ensino outros conhecimentos, pois argumentam que o perfil profissional, apresentado em muitas pesquisas, aponta que é necessário que as escolas e universidades busquem outros conhecimentos, como a capacidade de resolução de problemas complexos e estudo independente. Habilidades para trabalhos em grupo e a sensibilidade socioambiental.

Spers (2001, p.15-16) apud Araújo e Salgues (2005, p.04), afirma que os cursos de Administração, diante da contextura atual não devem privilegiar somente as técnicas correntes, tampouco "transmitam aos seus discentes somente as fórmulas prontas, mas que estejam preocupados também em trazer o lado crítico, dando aos alunos a possibilidade de aprender a aprender". Faz-se mister que o estudante tenha conhecimento da vida, do mundo, da ciência e da educação, e não apenas conhecimentos técnicos da área que atua ou pretende atual; uma finura de espírito para lidar com a pedagogia (educação) e a didática (a arte de ensinar) e tornar o aprendizado muito mais eficaz. 
A máxima de Freire (1992) apud Fación (2008, p.168), embora não aplicada exclusivamente ao ensino superior, mas ao ensino como um todo, diz que "quem forma se forma e re-forma ao formar quem é formado forma-se e forma ao ser formado", vem mostrar que a educação necessita de uma nova forma de ensinar a ensinar.

\subsection{PERSPECTIVAS EDUCACIONAIS}

De acordo com Gil (1997), são três as perspectivas em que o docente pode enfatizar em sala de aula: a perspectiva clássica, a perspectiva humanista e a perspectiva moderna.

A perspectiva clássica, segundo Gil (1997, p. 25), "em sua expressão mais extremada, vê os alunos como instrumentos passivos, capazes de aprender e aceitar orientações, mas muito imaturos para iniciar qualquer atividade significativa". Nessa perspectiva, o aluno passa a ser o sujeito passivo e o professor o sujeito ativo, sendo o ator principal desse processo, onde passa seu conhecimento e o aluno o aceita de forma determinante. Nesse contexto, a preocupação está em passar conteúdo a serem assimilados pelos alunos, "que leva os educandos à memorização mecânica do conteúdo" (CORRÊA, 2004, p.151).

A perspectiva humanista caracteriza uma reação ao rigorismo da perspectiva da escola clássica, "cuja teoria principal está em autores como Locke, Rousseau, Pestalozzi, Montessori, e especialmente o psicólogo humanista Carl Rogers.” (CORRÊA, 2004, p.150).

Nesta perspectiva, a liberdade e a eficiência são enfatizadas, de modo que seja aproveitado melhor o potencial dos alunos, centralizando o ensino no educando, que trazem consigo uma carga de experiências que podem ser aproveitadas e compartilhadas em sala de aula. Já o papel do professor, segundo Gil (1997), passa a ser de facilitador, ajudando o aluno a aprender.

A perspectiva moderna tende a conciliar as perspectivas clássica e humanista, enfatizando o processo ensino-aprendizagem (CORREAA, 2004, p.151), e tenta atrelar à ênfase no conteúdo que é dado pela perspectiva clássica o modo mais libertário enfatizado pela perspectiva humanista.

Segundo Gil (1997, p. 27), "esta perspectiva tornou-se muito influente a partir da década de 30 e inspirou muitos movimentos em prol das "escolas novas" e é tida em muitos meios como a mais adequada". Nesta perspectiva, o professor não deixa de ensinar, porém, passa também a valorizar as qualidades descritas pela escola humanista, inserindo o aluno como parte do processo de ensino. Outra característica desta perspectiva é a ênfase na pesquisa, fazendo-se mister para produzir uma melhora dos métodos e programas. 
O quadro 1 mostra de forma sucinta o contraste das três perspectivas mencionadas por Gil (1997, p.28).

\begin{tabular}{|c|c|c|}
\hline Perspectiva Clássica & Perspectiva Humanista & Perspectiva Moderna \\
\hline $\begin{array}{l}\text { Adaptação dos alunos aos } \\
\text { objetivos da escola } \\
\text { Certeza } \\
\text { Competição } \\
\text { Autocracia } \\
\text { Disciplina } \\
\text { Reprodução } \\
\text { Orientação para o } \\
\text { conteúdo } \\
\text { Ênfase no ensino }\end{array}$ & $\begin{array}{l}\text { Adaptação da escola às } \\
\text { necessidades dos alunos } \\
\text { Dúvida } \\
\text { Cooperação } \\
\text { Laissez-faire } \\
\text { Liberdade } \\
\text { Descoberta } \\
\text { Orientação para o método } \\
\text { Ênfase na aprendizagem }\end{array}$ & $\begin{array}{l}\text { Harmonização entre as } \\
\text { necessidades dos alunos } \\
\text { e os valores sociais } \\
\text { Probabilidade } \\
\text { Crescimento } \\
\text { Participação } \\
\text { Responsabilidade } \\
\text { Criatividade } \\
\text { Orientação para a solução } \\
\text { de problemas } \\
\text { Ênfase no processo } \\
\text { ensino-aprendizagem }\end{array}$ \\
\hline
\end{tabular}

Quadro 1 Contraste das perspectivas educacionais.

Fonte: Gil, 1997.

\section{APRESENTAÇÃO E ANÁLISE DOS DADOS COLETADOS}

Deste ponto em diante, serão apresentados ao leitor a analise baseada na coleta de dados. Ficarão expostos gráficos, e também uma breve descrição analítica-teórica, com em face de reforçar a busca e empenho em atingir os objetivos propostos para este estudo.

\subsection{TITULAÇÃO DOS DOCENTES}

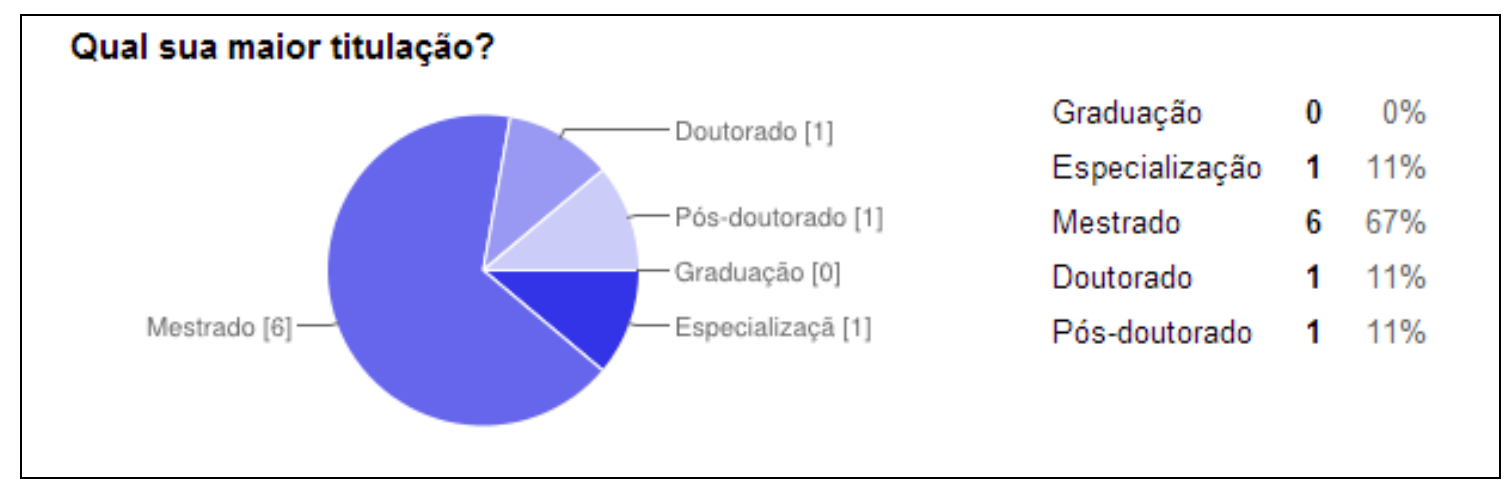

\section{Figura 1}

Fonte: Dados Primários.

Em suma, o gráfico acima demonstra que há uma procura, por parte dos professores, em aperfeiçoar-se. Dessa maneira, nota-se que o investimento em cursos de qualificação é uma premissa básica para aqueles que pretendem ingressar ou continuar a desenvolver suas atividades em docência. Sobre isto Imbernón (2010), tem muito a dizer quando afirma que a busca pelo conhecimento sempre foi um princípio que guiou os professores, desde o início da 
humanidade, no entanto a busca por novas teorias, novas práticas educacionais e modalidades de formação são muito mais recentes.

\subsection{EXPERIÊNCIA DO CORPO DOCENTE}

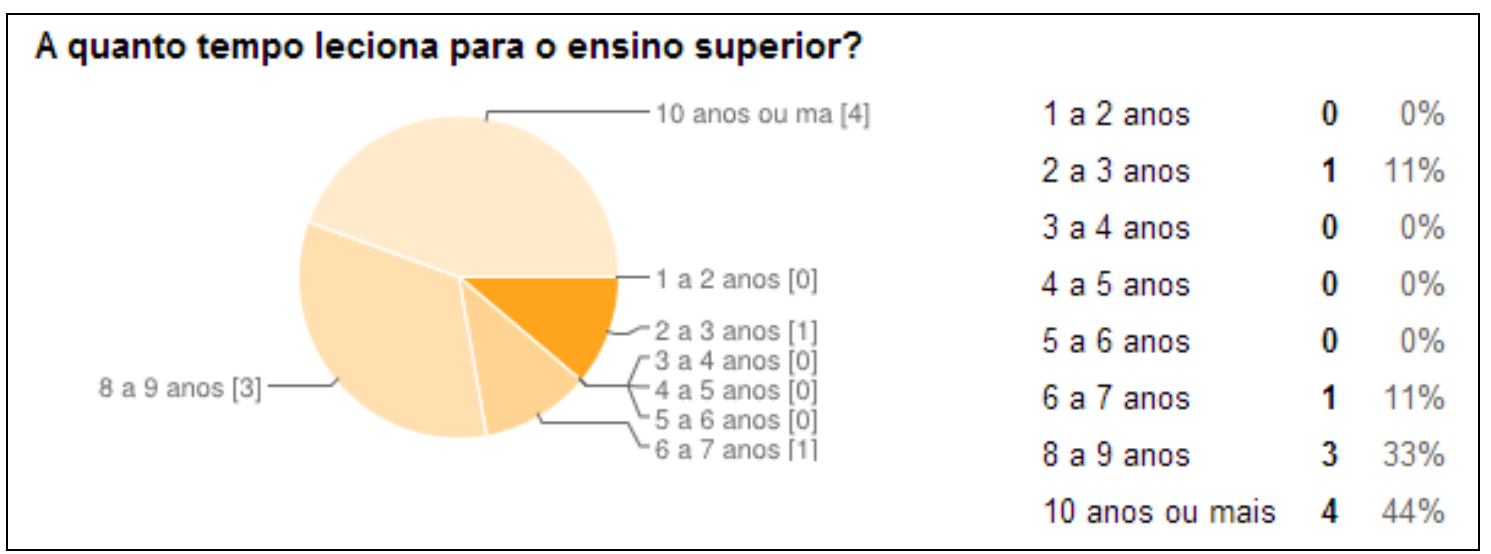

Figura 2

Fonte: Dados Primários.

No gráfico acima, é possível identificar que mais de $70 \%$ dos professores que atuam no curso de administração da UNESPAR/FAFIPAR tem longa experiência em sala de aula. $\mathrm{O}$ autor Demo (2012: 91) escreve que “o único livro didático insubstituível é o professor”, Ora, a experiência comprovada em sala de aula pode ser um forte aliado ao professor, pois leva-o ao patamar do conhecimento técnico, empírico, que pode ser reaplicado de maneira a aperfeiçoar a didática de maneira constante e linear. Sanz (2003) afirma que para o professor duas coisas são indispensáveis - Talento e Vocação - o primeiro pode ser compensado pela disciplina, pelas horas de estudo, no entanto a vocação é que faz o professor suportar decepções, e que ajuda-o a conviver em um mundo de diversidade tecnológica, cultural e multifacetado. 


\subsection{ESTRATÉGIAS UTILIZADAS EM SALA DE AULA}

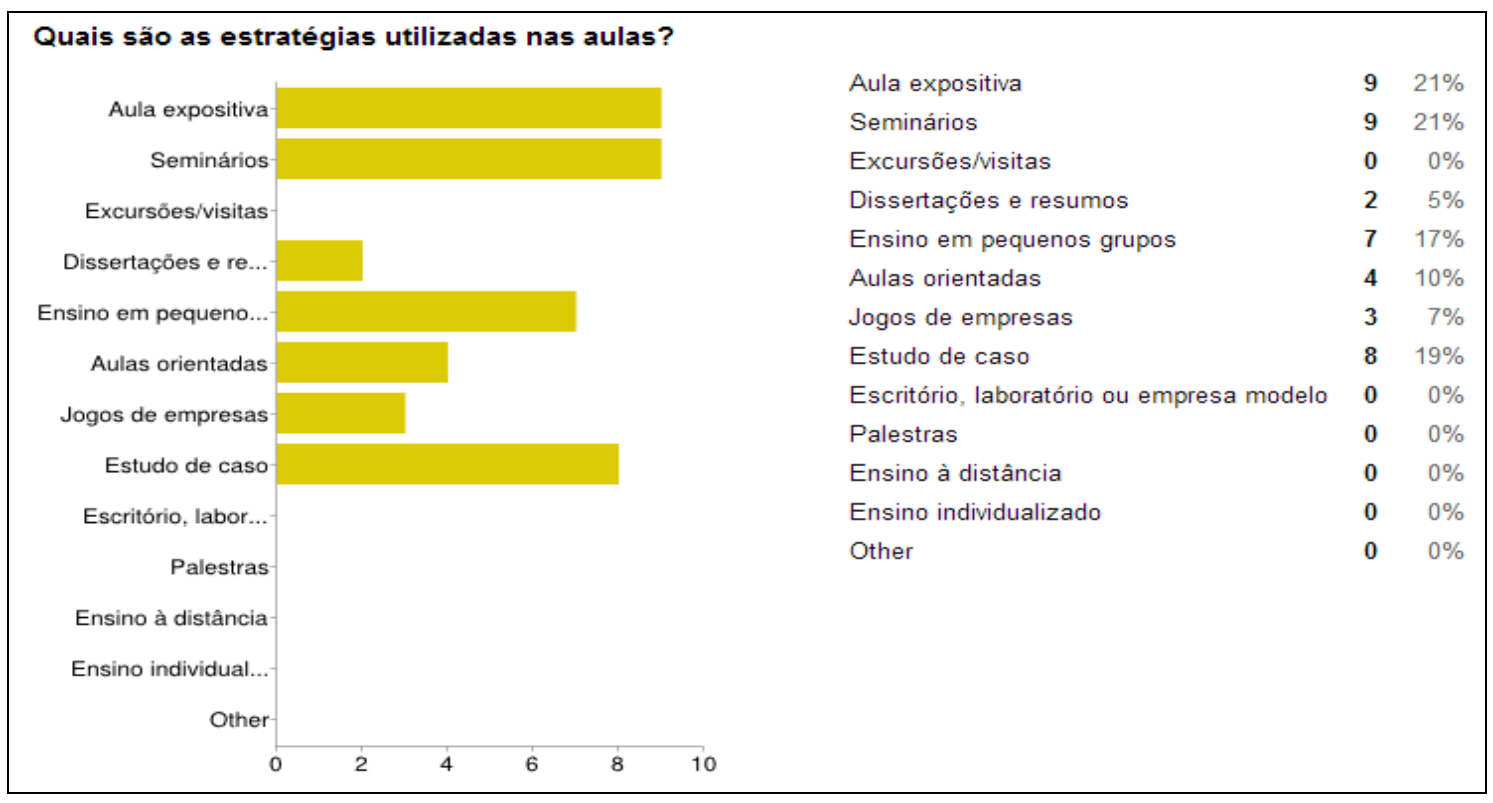

Figura 3

Fonte: Dados Primários.

É possível notar que o foco em aulas expositivas e discussões em pequenos grupos tem sido o carro chefe entre os docentes do curso de administração da UNESPAR/FAFIPAR, pode-se extrair desses dados a suposição de que ou os professores não estão ambientados com outros recursos não mencionados, ou estes não oferecem suporte o suficiente para elaboração e desenvolvimento de aulas condizentes com a realidade acadêmica, ou ainda, é possível dizer que o mal aproveitamento advém da dificuldade de sintetizar estratégias junto a instituição para oferecer novos suportes de ensino para os discentes, pois é plausível supor que a burocracia interna pode acarretar dificuldades na aplicação de tais estratégias. Hengemühle (2011) adverte que não é possível tolerar o professor que pauta-se na teoria como maneira de exemplificar a prática. Como exemplo, o autor pergunta aos seus leitores se entregariam um parente à um médico que tem apenas a teoria. E vai mais além, ao afirmar que o docente deve incorporar a teoria que acredita de maneira tal que possa fazer a diferença na vida de seus alunos. 


\subsection{TIPOS DE AVALIAÇÕES UTILIZADAS PELOS DOCENTES}

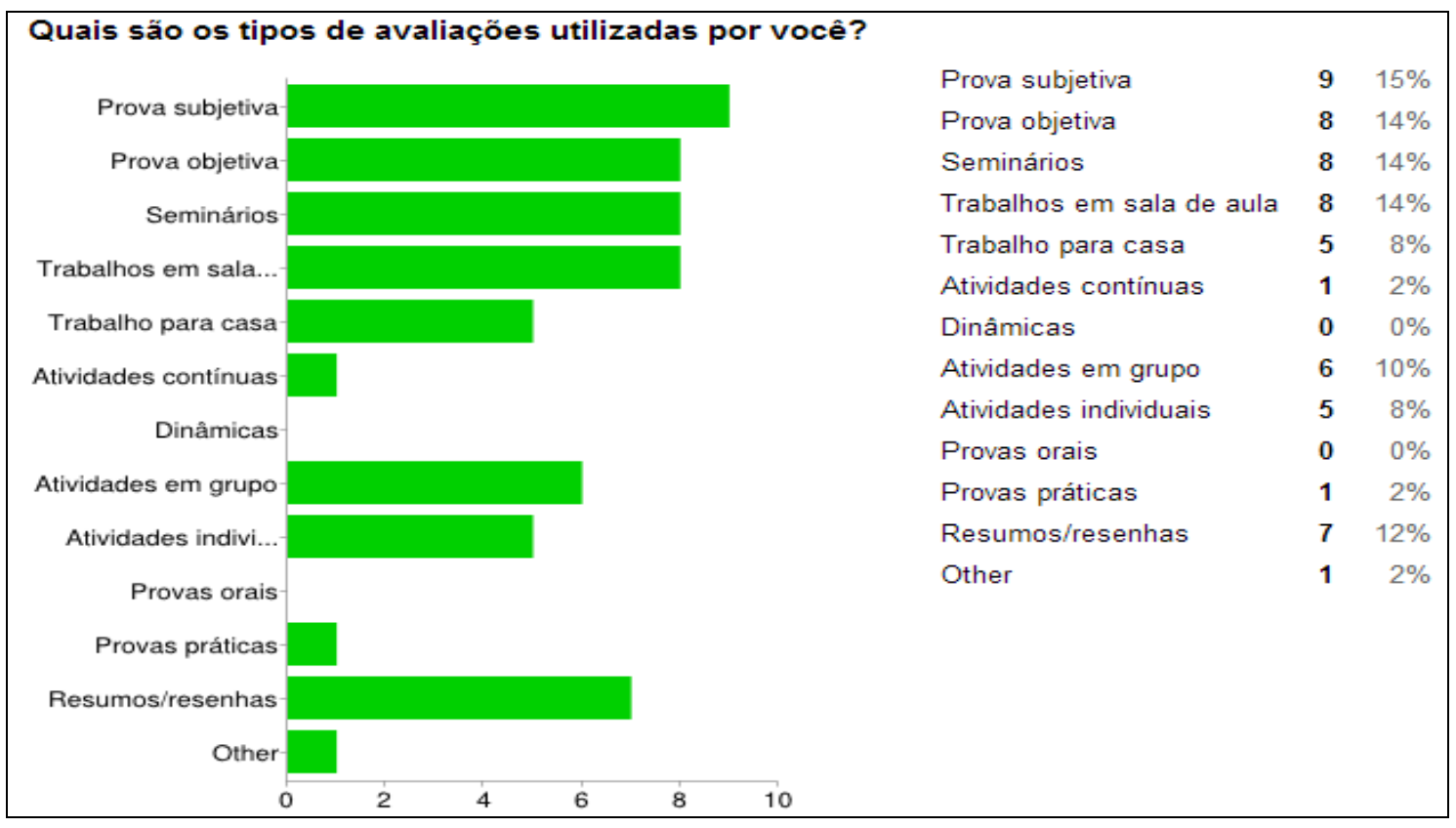

Figura 4

Fonte: Dados Primários.

Ainda existe, de acordo com os dados extraídos, uma preferencia por aplicações de provas de caráter quantitativo, embora exista o conceito de avaliação qualitativa, dever-se-ia questionar como é feita a estratégia de avalição das provas subjetivas.

A grande questão que talvez possa ser construída diante da analise do gráfico anterior é como realizar a avaliação de maneira qualitativa? E como mensurar se o aluno realmente atingiu o objetivo proposto pelo professor?

Ora, em um artigo que busca analisar o processo de ensino-aprendizagem de maneira global, estas questões são pontualizadas. No entanto, como a verificação cabe aos autores como forma de indiretamente atingir os objetivos propostos, busca-se nas palavras de Zabala e Arnau (2010), argumentação que possa construir uma resposta para questão levantada. Seguindo a concepção dos autores, a avaliação é apenas uma faceta em relação ao todo para discutir se o aluno realmente aprendeu. Tem-se que construir uma metodologia apropriada que vá desde a criação do plano de aulas até a finalização das aulas. É interessante discorrer que a construção da avaliação qualitativa deve estar intimamente integrada ao conteúdo programático do professor. A elaboração de indicadores de competências, quais serão os saberes desenvolvidos, podem nortear o docente ao elaborar uma avaliação subjetiva. Situações-problema é, do ponto de vista dos autores, uma ótima maneira de desenvolver a 
avaliação qualitativa. Criar indicadores de como o aluno conseguiu resolver os problemas propostos, sua criatividade, estratégia e maneira de agir, podem orientar o professor no momento da avaliação.

\subsection{METODOLOGIA APLICADA PELO DOCENTE}

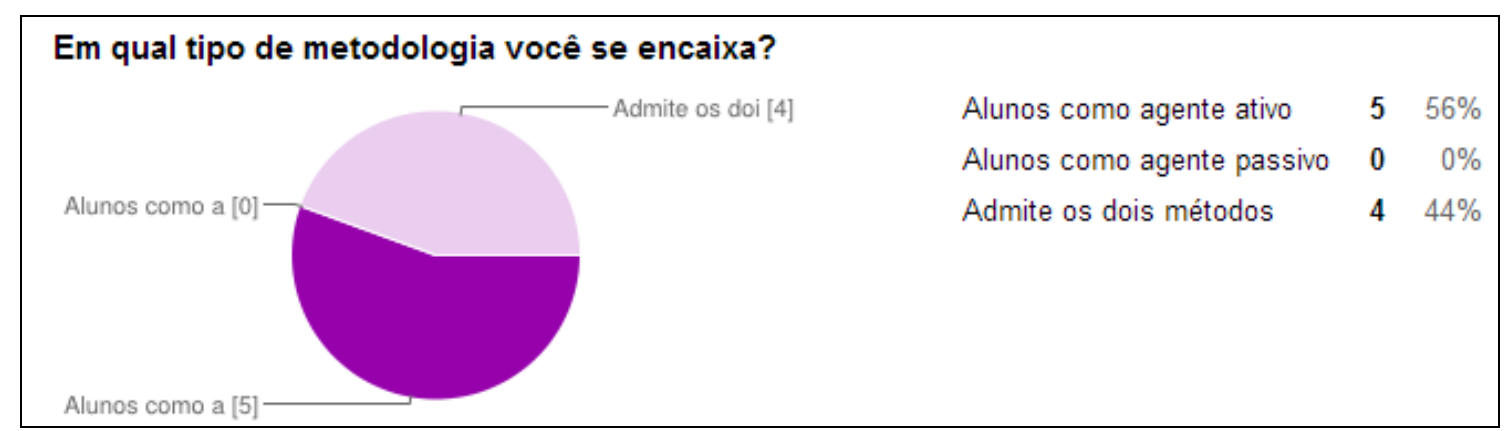

Figura 5

Fonte: Dados Primários.

Segundo afirmações constantes no gráfico 3.6, os docentes do curso de administração da UNESPAR/FAFIPAR, admitem que sua metodologia vê o aluno como agente ativo no processo de ensino aprendizagem.

A abordagem revelada no gráfico leva a entender que os professores estão buscando envolver os alunos em suas aulas, tornando-os sujeitos participativos. No entanto, é relevante demonstrar que existe um paradoxo evidente nas afirmações. É interessante notar que parte dos professores (56\%) afirmam ter os estudantes como agentes passivos, no entanto 44\% admitem utilizar as duas maneiras. É incoerente por si mesma a afirmação de admitir os dois métodos. Utilizando Sacristán (2011) como orientação teórica, o autor incorre no fato de que uma política construída para ser multidisciplinar, como é o caso do PDI da UNESPAR/FAFIPAR (2011: 28) quando este documento afirma que sua missão é "gerar e difundir o conhecimento científico, artístico-cultural, tecnológico e a inovação, nas diferentes áreas do saber, para a promoção da cidadania, da democracia, da diversidade cultural e do desenvolvimento humano e sustentável, em nível local e regional, estadual e nacional", não admite a passividade dos alunos. Vinyamata (2005) prega que deve haver uma relação de conflito (sadio) para a ampliação do conhecimento multidisciplinar, pois desta maneira haverá uma busca reflexiva sobre a construção do conhecimento e do cidadão. 


\subsection{SITUAÇÕES PRÁTICAS EM SALA DE AULA}

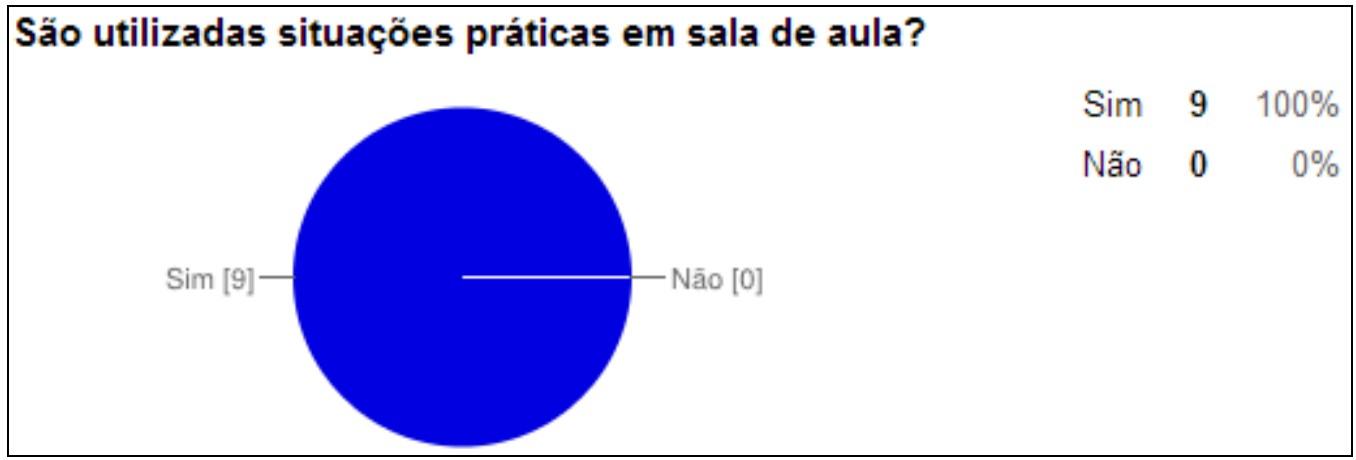

Figura 6

Fonte: Dados Primários.

Observa-se aqui a preocupação do docente em levar situações práticas para o aluno, de modo que este possa estar preparado para o mercado de trabalho, além de atuar como sujeito ativo, atrelando suas experiências ao aprendizado. Existe, deduzindo do gráfico acima, uma preocupação dos docentes em aproximarem os alunos à uma realidade que para eles não é cotidiana. A importância dessa ação educacional é interessante pelo ponto de vista de Zabala e Arnau (2010) e Vinyamata (2005) pois os autores discorrem que ao confrontar realidades, o individuo se vê tentado a refletir sobre o novo horizonte. A problemática proposta pode ser extremamente construtiva para o conhecimento do estudante, pois leva este a pensar de uma maneira nova, intuitiva e perspicaz para resolver a situação. Isso dá-lhe um "feedback" que será válido para todos os âmbitos em sua vivência.

\subsection{QUANTIDADE DE ALUNOS EM SALA DE AULA}

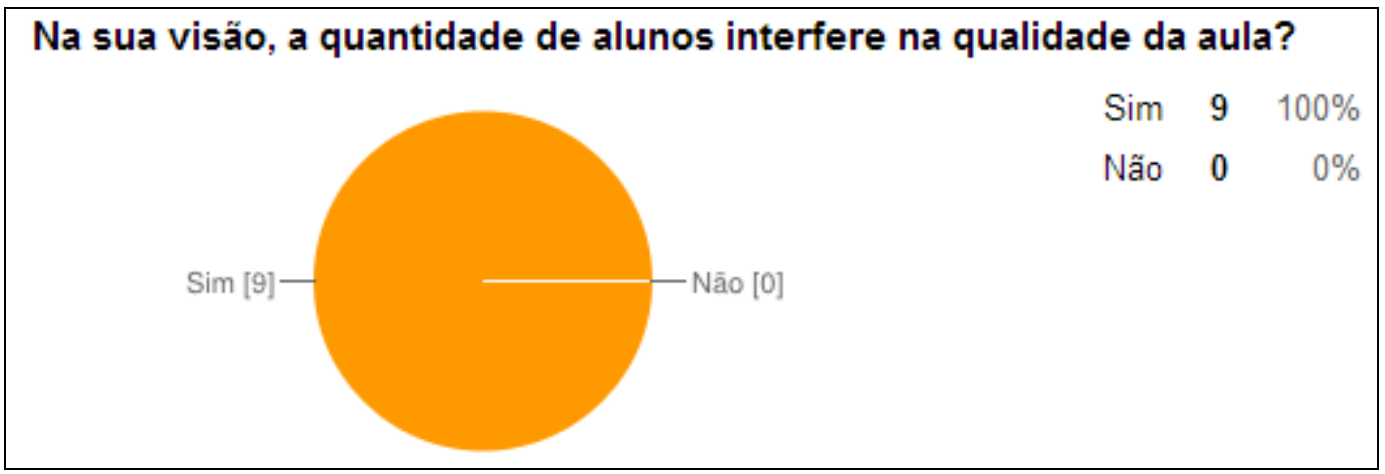

Figura 7

Fonte: Dados Primários.

É unânime entre os docentes, que a quantidade de alunos interfere diretamente na qualidade de ensino por eles aplicada. Sobre isso Demo (2012) reflete que há uma 
necessidade de superar a velha engrenagem da escola padrão existente no País. Para o autor, a qualidade do ensino somente será possível quando as novas estratégias de ensino, teorias e propostas pedagógicas forem efetivamente implantas em toda o processo educacional. De nada adianta lindas palavras em documentos se a prática em sala de aula demonstra que existe um abismo em relação a primeira. De fato, autores como Hengemühle (2011) atestam que inúmeras práticas modernas estão sendo incorporadas a velhos paradigmas, o que pode criar uma espécie "quimera educacional".

\subsection{NÚMERO IDEAL DE ALUNOS EM SALA DE AULA}

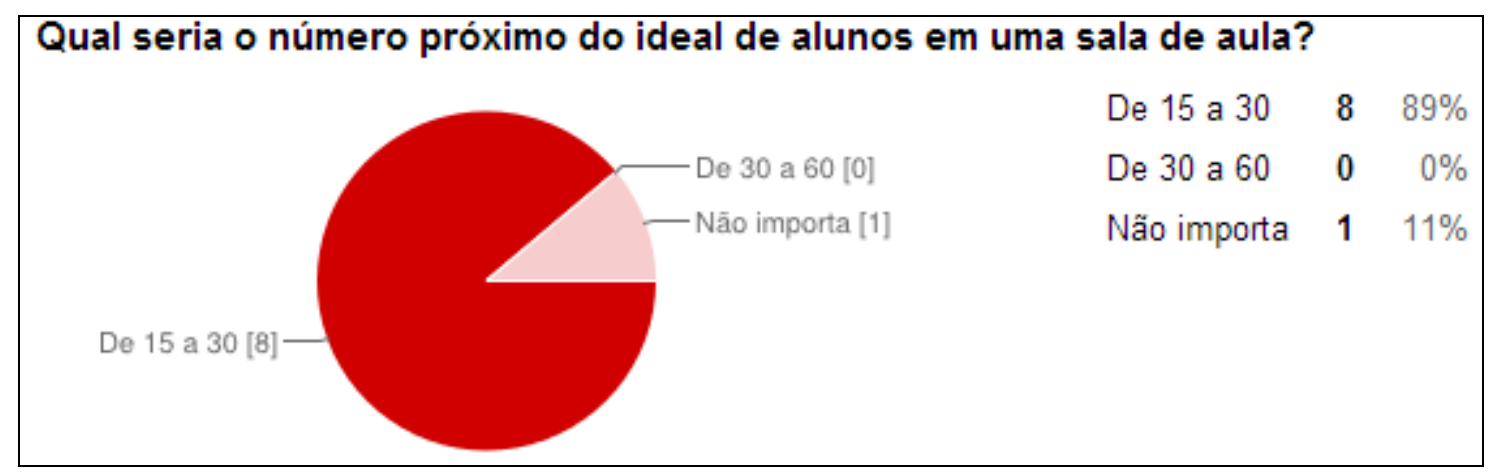

Figura 8

Fonte: Dados Primários.

Ainda buscando dados no gráfico anterior, este questionamento levanta entre os docentes qual o número ideal de acadêmicos, e fica evidenciado que 15 a 30 alunos seria o ideal, no entanto, este dado fica muito aquém da realidade, pois em sala é possível encontrar ao menos 40 alunos por sala, o que pode vir a dificultar a prática de alguns exercícios ou métodos mais personalizados que exijam um pouco mais de atenção por parte do professor. Replicando o que diz Hengemühle (2011) a importância de se ponderar uma quantidade máxima de alunos é fator decisivo para a validação da qualidade. Ora, Rossetti (2013) em seu livro "Introdução à economia" afirma que existe um ponto ótimo para processos produtivos, produtos, etc. Para a educação não é diferente, deve-se analisar a capacidade de professor, dos alunos, da sala de aula, enfim tudo que quantitativamente possa interferir na qualidade. 


\subsection{NÚMERO REAL DE ALUNOS EM SALA DE AULA}

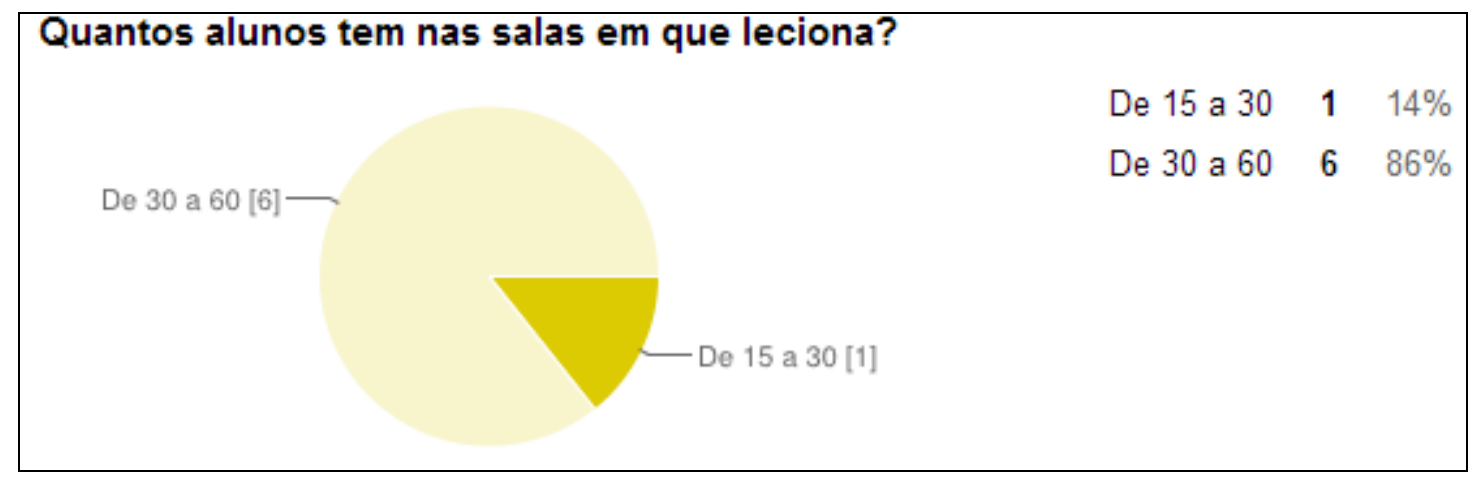

Figura 9

Fonte: Dados Primários.

Apresentado como os dados anteriores, este gráfico vem reforçar a afirmação anterior referente a quantidade de alunos em sala de aula. É possível verificar que mais de $80 \%$ das salas de aula estão acima da capacidade considerada ideal pelos professores. Utilizando como comparativos, os gráficos 3.8; 3.9 e 3.10, deixam evidente a falácia aplicada pelo PDI, uma vez que uma estruturação de curso busca identificar as reais necessidades dos professores para esses possam, de certa forma, desempenhar suas funções de maneira eficiente, eficaz e efetiva. A pergunta que se lança é, será que o pdi é mais um documento que, como tantos outros, será um manual de instruções que ninguém consegue seguir? É uma resposta muito ampla, no entanto Marchesi (2004) afirma que existe um problema maior do que apenas redigir documentos. A problematização central está no sincretismo, como anteriormente comentado, que funde passado e presente, buscando construir um futuro totalmente diferente. Ora, vive-se dessa maneira a experiência do Gato de Schrödinger, quando se fazem probabilidades para definir um futuro incerto. $\mathrm{O}$ autor discorre que a mudança deve ser interna, é preciso conhecer a realidade educacional a fundo, verificar como a escola funciona e assim propor mudanças consistentes. É defendido que as propostas educacionais priorizam o aluno em detrimento dos outros segmentos que também fazem parte do processo ensinoaprendizagem. 


\subsection{AMBIENTE DE TRABALHO}

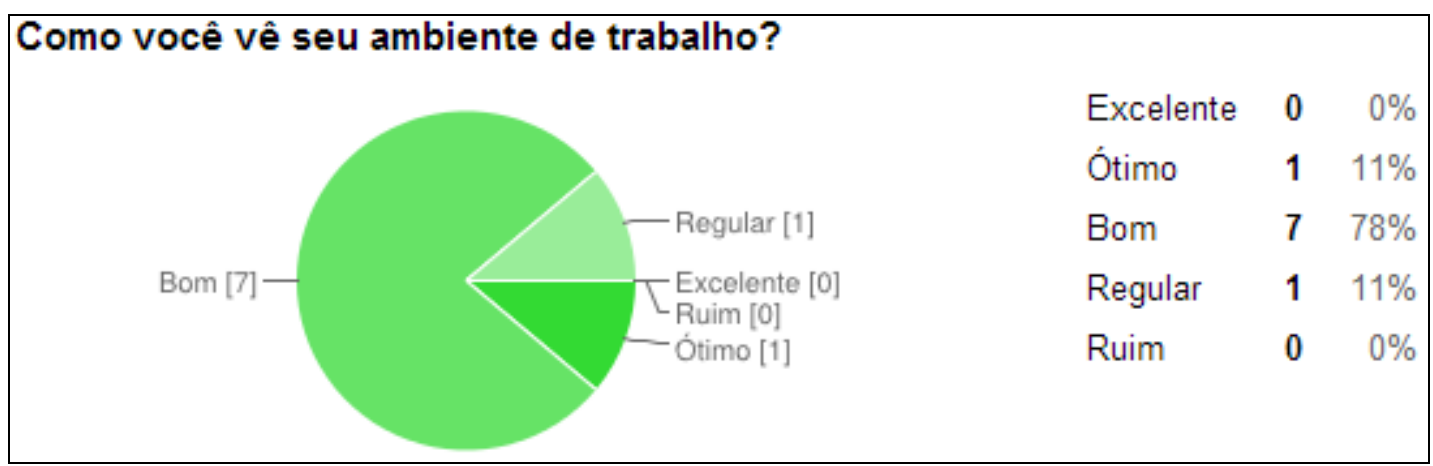

Figura 10

Fonte: Dados Primários.

Mesmo com algumas afirmações negativas em relação à capacidade de alunos em sala de aula, os professores veem em seu ambiente de trabalho um clima bom, em partes se deve ao relacionamento desenvolvido pelo método de ensino aprendizagem adotado pelos professores, que priorizam os alunos como agentes atuantes durante este processo. Vinyamata (2005) revela que existe uma concepção de inter-relação entre o aluno e o professor. A partir disso é possível notar que mesmo uma escola pouco estruturada ainda pode oferecer um ambiente de convivência social. Isso é uma característica do professor. O individuo que almeja ser professor desenvolve vínculos com seus alunos, muitas vezes ultrapassando os muros da instituição de ensino, trata-se de um laço professor-aluno que pode florescer para novas perspectivas de ensino aprendizagem, Sacristán (2011).

\subsection{CURSOS DISPONILIZADOS PELA INSTITUIÇÃO AO CORPO DOCENTE}

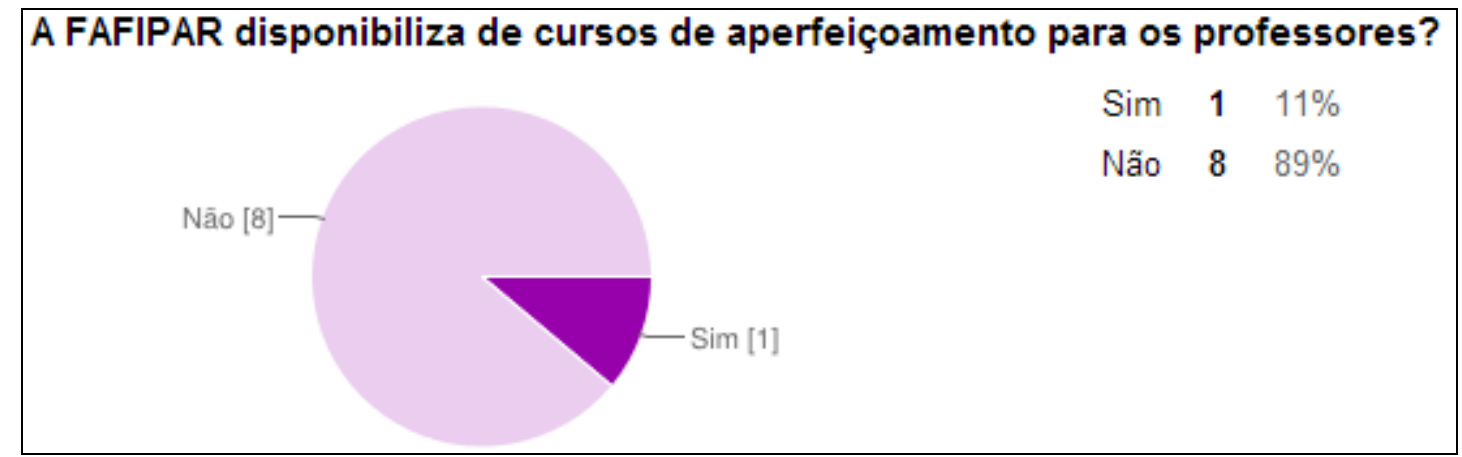

Figura 11

Fonte: Dados Primários.

A afirmação em evidencia torna preocupante a alegação por parte dos docentes de não haver cursos de aperfeiçoamento oferecido pela UNESPAR/FAFIPAR. Observando por este 
prisma, é possível identificar onde está a falha na utilização de todas as ferramentas de ensino de maneira equitativa pelos docentes do curso. Imbernón (2010) mostra-se inconformado com situações como a representada pelo gráfico, pois o autor afirma que o avanço nos processos de educação continuada não devem ser lineares. Para este autor, há muito que deve ser questionado, mas que a estrutura de ensino ignora, pois acarretará em uma reestruturação do ensino em todos os seus níveis, o que não é interessante, ao menos não agora, para o poder controlador da máquina do estado.

Ao colocar em prática uma visão sistêmica sobre os dados apresentados, é possível evidenciar que existe uma mescla das diversas teorias e escolas pedagógicas existentes. Ora, uma ruptura, por mais abrupta que seja não deixa de evidenciar fatores dos conhecimentos anteriores, pois é o processo, e não a finalidade que se presta ao objetivo proposto. Morin (2003) discorre que o processo de conhecimento deve guiar o aluno para uma nova concepção de realidade. Jonh Dewey (1950) com o modelo de pedagogia da ação, que defende a individualidade do sujeito, para ele não o processo de impelir alguém ao conhecimento, através de praticas impositivas, é um crime cometido contra a educação, o conhecimento e o ser humano. Essa visão que se contrapõe à de Durkheim, ajudou a desenvolver a ação ativa do aluno, onde o conhecimento é fruto de uma serie de ações, criticas e reflexões do aluno. $\mathrm{O}$ Construtivismo de Piaget e Gréco (1974) e Vygotsky (1984) que sugere que o aluno deve reconstruir a situação para que entenda o processo e finalmente o motivo pelo qual existe, são facetas de um processo continuo no tempo. A situação que se apresenta, ao se analisar o padrão inferido à realidade de ensino do curso de administração da FAFIPAR/UNESPAR, campus Paranaguá, dá provas de que o processo ainda está ocorrendo. O passando e o presente se cruzam, se interpelam, na busca constante para um aperfeiçoamento. Até onde isso é positivo ninguém pode definir, mas ao se analisar o pensamento de Morin (2003) chega-se a uma concepção de que é necessário fazer algo, caso contrário a educação poderá perecer no limbo da repetição, das mesmices e contrassensos que existem.

Vergara (2003) apresenta algumas ferramentas muito uteis para serem utilizadas no ensino em administração, quais sejam, o estudo de caso, que é tão difundido entre os cursos de administração; caso de negócios em tempo real, fazendo com que os alunos assumam o papel de consultor; estudos de casos hipertextuais, onde, embora pareça um estudo de caso convencional,. Utilizam-se recursos tecnológicos; estudos de casos elaborados por estudantes, sendo que os próprios alunos tem a função de criar e resolver situações; crole playing, aqui é realizada uma simulação, e os discentes assumem papéis gerenciais para o enfrentamento de 
determinada situação; jogos de negócios, muito utilizado também pelos cursos de graduação em administração; monitoria de projetos sociais, sendo que os professores e estudantes podem entrar em contato com a sociedade, conhecer a fundo os problemas e tentar resolvê-los; e, além das já citadas, as dinâmicas em grupo, onde a interação entre os indivíduos será constante.

\section{CONSIDERAÇÕES FINAIS}

Este estudo buscou evidenciar as práticas de ensino utilizadas pelos professores do curso Administração da UNESPAR/FAFIPAR com o intuito de traçar um perfil profissional de seus docentes. Através da pesquisa, pode-se observar, em primeiro plano, a preocupação do docente com a educação científica, e que o corpo de docentes da UNESPAR/FAFIPAR conta com professores com uma experiência significativa em sala de aula. Considerando os recursos utilizados em sala (quadro, giz, livros, vídeos, em sua maioria), aliados às estratégias de seminários, estudo de caso e aulas expositivas, pode-se observar uma tendência mais voltada à escola moderna por parte dos professores. Além do mais, todos os docentes afirmaram considerar o aluno como sujeito ativo, seja integralmente ou parcialmente durante suas aulas. A importância desse foco está na conscientização de que alunos e professores são responsáveis pelo processo de aprendizagem, sendo cada um responsável por uma parte deste processo.

Outro ponto importante da pesquisa foi o relato das condições para se colocar em práticas atividades mais voltadas às necessidades dos alunos, como visitas in loco (excursões) e empresas modelos, que aproximariam o educando à realidade trazendo novas experiências e contribuindo de maneira efetiva e eficaz para o processo de aprendizagem, além das salas de aula serem consideradas lotadas, impossibilitando ou dificultando a prática de algumas atividades que exigem um nível de atenção do professor, como mediador, bem maior e mais personificado.

Para ratificar o perfil moderno dos professores, estes mostram uma preocupação no processo cognitivo e na construção do saber do aluno em suas avaliações, que não consideram apenas a memorização do conteúdo nas provas objetivas e sim, avaliam seus educandos através das mais variadas formas, como os seminários, trabalhos em sala, resumos, evidenciando a perspectiva moderna que mostra o professor como facilitador da aprendizagem. 
$\mathrm{Na}$ analise positivista do assunto proposto, chegasse a uma definição de que o perfil do professor que atua no curso de Administração da UNESPAR/FAFIPAR, campus Paranaguá, é a humanista moderna, tão defendida por Morin (2003), Guerreiro Ramos (1958) e Freire (2003) quando avistam um futuro onde o individuo conseguirá ser dono de seu eu, questionador do sistema, o homem parentético de Guerreiro Ramos, o ser pensante de Freire e, aquele que é capaz de transcender a realidade, verifica-la de maneira ampla e sistemática como diz Edgar Morin. Para esses autores, que, embora advindos de culturas e momentos diferentes, mas que compartilham uma visão similar, a grande mudança ocorrerá quando o ser humano conseguir interagir de maneira filosófica com a realidade. Talvez o curso de Administração da UNESPAR/FAFIPAR, no campus de Paranaguá, ainda esteja distante de atingir este objetivo, porém no caminho certo.

\section{REFERÊNCIAS}

ALMEIDA, C; DIAS, E. T. Dal Mas. EDUCAÇÃO: ENTRE O PROSÁICO E O POÉTICO. Jundiaí - SP. Paco Editorial: 2011.

ARAÚJO, F. R. de S.; SALGUES, L. J. de V. A PROBLEMÁTICA DA INTERDISCIPLINARIDADE NOS CURSOS DE GRADUAÇÃO EM ADMINISTRAÇÃO: PROPOSTA PARA REFLEXÃO TEÓRICA. VIII SemeAd FEAUSP. 2005. Disponível em:

$<$ http://www.ead.fea.usp.br/semead/8semead/resultado/trabalhospdf/64.pdf $>$. Acesso em: 09 jun. 2014.

CFA. HISTÓRIA DA ADMINISTRAÇÃO. Disponível em: < http://www.cfa.org.br/administracao/historia-da-profissao > . Acesso em 10 jun. 2014.

COMENIUS, M. F. trad. BENEDETTI, I. C. DIDÁTICA MAGNA. $4^{\mathrm{a}}$ ed. - São Paulo: WMF Martins Fontes, 2011.

CORRÊA, J. T. ENSINO JURÍDICO: REFLEXÕES DIDÁTICO-PEDAGÓGICAS. rev. direito em debate, Ano XII, n²2, jul./dez. 2004, p.147-141.

DEMO, P. DESAFIOS MODERNOS DA EDUCAÇÃO. $18^{\mathrm{a}}$ ed. - Petrópolis, RJ: Vozes, 2012.

DEWEY, J. LÓGICA: TEORÍA DE LA INVESTIGACIÓN. México: Fundo de Cultura, 1950.

FACIÓN, J. R. INCLUSÃO ESCOLAR E SUAS IMPLICAÇÕES. $2^{\text {a }}$ Ed. Curitiba: IBPEX, 2008. 
FILHO, E. E.; RIBEIRO, L. R. de C. INOVANDO NO ENSINO DE ADMINISTRAÇÃO: UMA EXPERIÊNCIA COM A APRENDIZAGEM BASEADA EM PROBLEMAS (PBL). Cadernos EBAPE.BR. n especial. 9p. Disponível em:

$<$ http://bibliotecadigital.fgv.br/ojs/index.php/cadernosebape/article/viewFile/5431/4165>. Acesso em 10 jun. 14.

FREIRE, P. PEDAGOGIA DA AUTONOMIA: SABERES NECESSÁRIOS À PRÁTICA EDUCATIVA. 26 Edição. Editora Paz e Terra, São Paulo, 2003.

GIL, A. C. MeTOdOLOGIA DO ENSINO SUPERIOR. 3. ed. São Paulo: Atlas, 1997.

GUERREIRO RAMOS, A. A REDUÇÃO SOCIOLÓGICA: INTRODUÇÃO AO

ESTUDO DA RAZÃO SOCIOLÓGICA. Rio de Janeiro, MEC/lseb, 1958.

HENGEMÜHLE, A. GESTÃo de ENSINO E PRÁTICAS PEDAGÓGICAS. $7^{\mathrm{a}} \mathrm{ed}$. Petrópolis, RJ: Vozes, 2011.

IMBERNÓN, F. FORMAÇÃO CONTINUADA DE PROFESSORES. Porto Alegre: Artmed, 2010.

LAKATOS, E. M; MARCONI, M. de A. FUNDAMENTOS DE METODOLOGIA CIENTÍFICA. 7ª ed - São Paulo : Atlas 2010.

LIMA, M. de L. R. de. O SURGIMENTO DA DISCIPLINA METODOLOGIA DIDÁTICA DO ENSINO SUPERIOR COMO PROJETO DE FORMAÇÃO DOCENTE. Educ. Rev., Belo Horizonte, n. 20-25, jun. 1997 . Disponível em < http://educa.fcc.org.br/pdf/edur/n20-25/n20-25a04.pdf> . Acesso em 09 jun. 2014.

MARCHESI, A. O QUE SERÁ DE NÓS, OS MAUS ALUNOS? Trad. ROSA, E. - Porto Alegre - RS: Artmed, 2006.

MORIN, E. A CABEÇA BEM-FEITA: REPENSAR A REFORMA, REFORMAR O PENSAMENTO. Trad. JACOBINA, E. - 8 a ed. -Rio de Janeiro: Bertrand Brasil, 2003.

PIAGET, J. e GRÉCO, P. APRENDIZAGEM E CONHECIMENTO. Rio de Janeiro - RJ: Freitas Bastos, 1974.

PINTO, V. R. R.; MOTTER, M. D. Jr. UMA ABORDAGEM HISTÓRICA SOBRE O ENSINO DE ADMINISTRAÇÃO NO BRASIL. Revista Pensamento Contemporâneo em Adminitração. Rio de Janeiro v. 6 n. 4 out./dez. 2012. pp.1-28.

ROSSETI, J. P. INTRODUÇÃO À ECONOMIA. $20^{\mathrm{a}}$ ed. - 11 reimpr. - São Paulo: Atlas, 2013.

SACRISTÁN, J. G. et al. EDUCAR POR COMPETÊNCIAS: O QUE HÁ DE NOVO? Porto Alegre, RS: Artmed, 2011.

SANZ, L. A. PROCEDIMENTOS METODOLÓGICOS: FAZENDO CAMINHOS. Rio de Janeiro: Ed. Senac Nacional, 2003. 
UNESPAR, Universidade Estadual do Paraná. PLANO DE DESENVOLVIMENTO INSTITUCIONAL 2012 - 2016. Paraná, 2011.

VERGARA, S. C. REPENSANDOA RELAÇÃO ENSINOAPRENDIZAGEMEM ADMINISTRAÇÃO: ARGUMENTOS TEÓRICOS, PRÁTICAS E RECURSOS. EBAPE/FGV o\&s - v.10 - n.28 - Setembro/Dezembro - 2003

VINYAMATA, E. trad. ROSA, E. APRENDER A PARTIR DO CONFLITO:

CONFLITOLOGIA E EDUCAÇÃO. Porto Alegre: Artmed, 2005.

VYGOTSKY, L. S. A FORMAÇÃO SOCIAL DA MENTE. São Paulo: Martins Fontes, 1984.

ZABALA, A; ARNAU, L. COMO APRENDER E ENSINAR COMPETÊNCIAS. Porto Alegre - RS: Artmed, 2010. 